SFB

Exchange rate policy under

823

sovereign default risk

Andreas Schabert

Nr. 7/2011

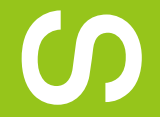

$\infty$

$\longrightarrow$

ర

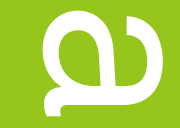

(1)

1

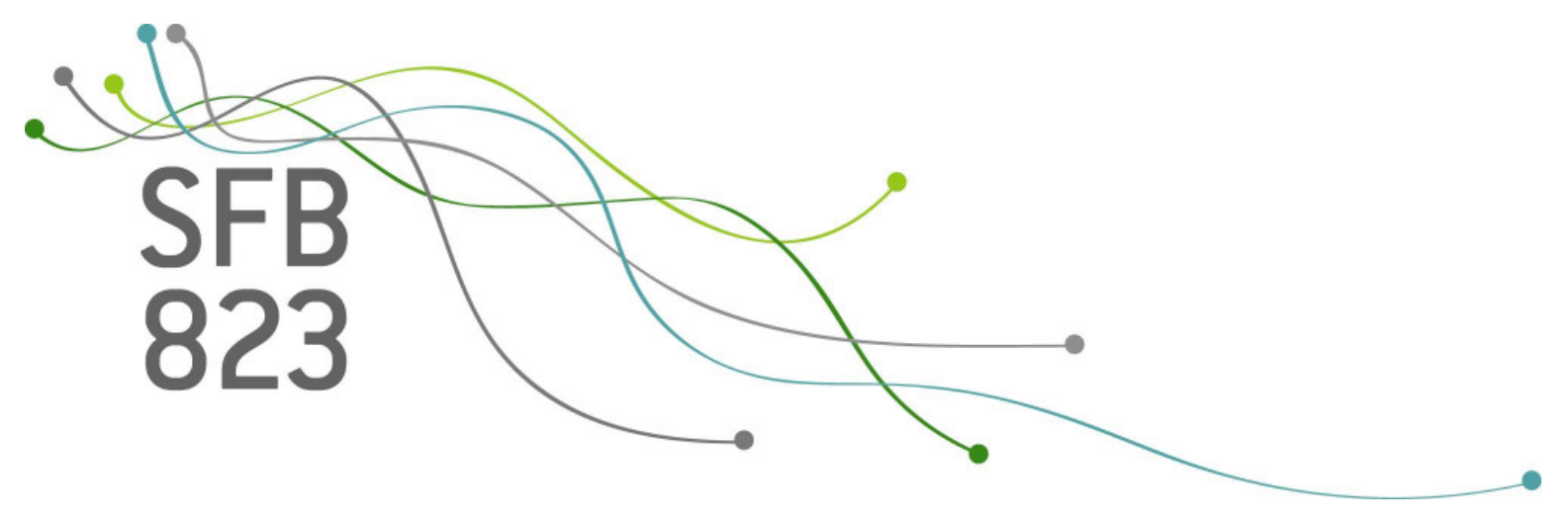





\title{
Exchange rate policy under sovereign default risk ${ }^{*}$
}

\author{
Andreas Schabert, ${ }^{\ddagger}$ TU Dortmund University and University of Amsterdam ${ }^{\S}$
}

\begin{abstract}
We examine monetary policy options for a small open economy where sovereign default might occur due to intertemporal insolvency. Under interest rate policy and floating exchange rates the equilibrium is indetermined. Under a fixed exchange rate the equilibrium is uniquely determined and independent of sovereign default.
\end{abstract}

\section{Introduction}

In response to the financial crises, expansionary fiscal policies in many countries have led to a surge in public debt. This has raised fears of sovereign default even for countries that did not default in their recent history. Since public debt in industrialized countries and even in emerging market economies are to a substantial fraction denominated in domestic currency (see [3]), the real debt burden cannot directly be lowered by currency devaluations. This leads to the question how exchange rate policies should be conducted under sovereign default risk.

In this paper, we show that an exchange rate peg can shield the allocation of resources against default risk. We apply a simple approach to sovereign default, which is based on the "Fiscal Theory of Sovereign Risk" of [7], and develop a small open economy model with a transactions friction. The government does not guarantee full debt repayment, such

${ }^{*}$ JEL classification: E52, E63, F31, F41

Keywords: Exchange rate peg, interest rate policy, equilibrium determination, sovereign default, public debt

${ }^{\dagger}$ The financial support of the Deutsche Forschungsgemeinschaft (SFB 823, "Statistical modelling of nonlinear dynamic processes") is gratefully acknowledged.

${ }^{\ddagger}$ TU Dortmund University, Department of Economics, Vogelpothsweg 87, 44227 Dortmund, Germany, Phone: +49 231755 3288, Email: andreas.schabert@udo.edu.

$\S$ This version: January 2011. 
that households' investments in government bonds depend on their default expectations. A policy of setting the interest rate and letting the exchange rate float is then insufficient to uniquely determine the equilibrium, which corresponds to the result in [5] for a closed economy.

If, however, the exchange rate is fixed, the equilibrium allocation is uniquely determined and shielded against default expectations. The simple reason is that by pegging the exchange rate, the home economy can "import" risk-free foreign interest rates. This novel argument in favor of fixed exchange rates relates to the idea of determining the price level by pegging the exchange rate and to the "Fiscal Theory of the Price Level" applied for open economies (see [4] and [1]), which typically disregard the possibility of default.

\section{The model}

This section presents a small open economy version of the model in [5] with a cashcredit good distortion and a labor income tax. Following the "Fiscal Theory of Sovereign Default" (see [7]), we assume that tax revenues do not necessarily suffice to fully serve debt obligations.

There exists a continuum of infinitely lived and identical domestic households of mass one. Their utility increases in consumption $c_{t}$ and decreases in working time $n_{t}$, and their lifetime utility is

$$
\sum_{t=0}^{\infty} \beta^{t}\left[\log c_{t}-\psi n_{t}\right],
$$

where $\beta \in(0,1)$ denotes the discount factor. Consumption is an aggregate of domestically produced goods $c_{H}$ and foreign goods $c_{F}: c_{t}=\gamma c_{H, t}^{1-\vartheta} c_{F, t}^{\vartheta}$, where $0 \leq \vartheta<1$ and $\gamma=$ $\left[\vartheta^{\vartheta}(1-\vartheta)^{1-\vartheta}\right]^{-1}$. For a given level of aggregate consumption, the cost minimizing demand for the goods of home and foreign origin are given by

$$
c_{H, t}=(1-\vartheta)\left(P_{H, t} / P_{t}\right)^{-1} c_{t}, \quad c_{F, t}=\vartheta\left(P_{F, t} / P_{t}\right)^{-1} c_{t},
$$

where $P_{H, t}$ and $P_{F, t}$ are the price indices of the domestically produced and foreign consumption goods, respectively. The price index of the aggregate consumption good is then $P_{t}=P_{H, t}^{1-\vartheta} P_{F, t}^{\vartheta}$. We assume that the law of one price holds, such that $P_{H, t}=$ $S_{t} P_{H, t}^{*}$ and $P_{F, t}=S_{t} P_{F, t}^{*}$, where $P_{H, t}^{*}\left(P_{F, t}^{*}\right)$ is the price of home (foreign) goods expressed in foreign currency and $S_{t}$ is the nominal exchange rate. 
Households are initially endowed with domestic government bonds $B_{-1}^{h}>0$ and money $M_{-1}>0$. They can further invest in a full set of internationally traded state contingent claims that deliver one unit of foreign currency in each state. Since we do not model heterogeneity or uncertainty (for simplicity), this is equivalent to consider internationally traded risk-free bonds $F_{t}$, which are traded at $1 / R_{t}^{*}$ units of foreign currency and deliver one unit of foreign currency. The budget constraint is

$$
B_{t}^{h} R_{t}^{-1}+S_{t} F_{t}\left(R_{t}^{*}\right)^{-1}+M_{t} \leq\left(1-\delta_{t}\right) B_{t-1}^{h}+S_{t} F_{t-1}+M_{t-1}+\left(1-\tau_{t}\right) P_{t} w_{t} n_{t}-P_{t} c_{t}+\Gamma_{t}
$$

where $w_{t}$ denotes the real wage rate, $\tau_{t} \in[0,1]$ a labor income tax rate, and $\Gamma_{t}$ firms' profits. Domestic government bonds exhibit the period $t$ price $1 / R_{t}$ and lead to a payoff of $1-\delta_{t+1}$ units of domestic currency in $t+1$, where the default rate $\delta_{t}$ depends on the intertemporal government (in-)solvency (see [7]).

In each period, the asset market opens before the goods market. Money serves as a means of payment in both markets. In the asset market, households receive cash payoffs $\left(1-\delta_{t}\right) B_{t-1}^{h}+S_{t} F_{t-1}$ and spend the amount $\left(B_{t}^{h} / R_{t}\right)+S_{t} F_{t}\left(R_{t}^{*}\right)^{-1}$ on interest bearing assets, such that their stock of domestic currency is reduced by $Z_{t}=\left(B_{t}^{h} / R_{t}\right)-$ $\left(1-\delta_{t}\right) B_{t-1}^{h}+S_{t}\left[F_{t}\left(R_{t}^{*}\right)^{-1}-F_{t-1}\right]$ when they enter the goods market. Hence, they face the following cash constraint

$$
P_{t} c_{t} \leq M_{t-1}-Z_{t}
$$

The household maximizes (1) subject to (3), (4), a no-Ponzi game condition on international borrowing and $B_{t}^{h} \geq 0$, given $F_{-1}=0$ and $B_{-1}^{h}>0$, leading to the first order conditions

$$
\begin{aligned}
\psi c_{t} & =\left(1-\tau_{t}\right) w_{t} /\left[R_{t}\left(1-\delta_{t+1}\right)\right], \\
c_{t+1} / c_{t} & =\beta\left(1-\delta_{t+1}\right) R_{t} / \pi_{t+1}, \\
c_{t+1} / c_{t} & =\beta\left(q_{t+1} / q_{t}\right) R_{t}^{*} / \pi_{t+1}^{*},
\end{aligned}
$$

(4), and $\mu_{t}\left(M_{t-1}-Z_{t}-P_{t} c_{t}\right) \geq 0$, where $\mu_{t}$ is the multiplier on (4) satisfying $\mu_{t}=$ $\left(R_{t}\left(1-\delta_{t+1}\right)-1\right) \geq 0, \pi_{t}^{*}$ the foreign inflation rate $\pi_{t}^{*}=P_{t}^{*} / P_{t-1}^{*}$, and $q_{t}=S_{t} P_{t}^{*} / P_{t}$ the real exchange rate. Combining (6) and (7) leads to a "risk" adjusted uncovered interest 
rate parity UIP condition

$$
\left(1-\delta_{t+1}\right) R_{t}=\left(S_{t+1} / S_{t}\right) R_{t}^{*}
$$

Further, (3) holds with equality and the transversality conditions are satisfied,

$$
\lim _{t \rightarrow \infty}\left(b_{t}^{H} / R_{t}\right) \Pi_{i=1}^{t} \pi_{t+i} /\left[\left(1-\delta_{t+i}\right) R_{t+i-1}\right]=0
$$

and $\lim _{t \rightarrow \infty}\left(q_{t} f_{t} / R_{t}^{*}\right) \Pi_{i=1}^{t} \pi_{t+i}^{*} /\left[\left(q_{t+i} / q_{t+i-1}\right) R_{t+i-1}^{*}\right]=0$.

We assume that preferences of foreign households correspond to preferences of domestic households. Hence, foreign demand for domestically produced consumption goods $c_{H, t}^{*}$ and the foreign consumption goods $c_{F, t}^{*}$ satisfy $c_{H, t}^{*}=\vartheta^{*}\left(P_{t}^{*} / P_{H, t}^{*}\right) c_{t}^{*}$ and $c_{F, t}^{*}=\left(1-\vartheta^{*}\right)\left(P_{t}^{*} / P_{F, t}^{*}\right) c_{t}^{*}$, where $\vartheta^{*} \in(0,1)$ and $c_{t}^{*}$ is aggregate foreign consumption. Foreign households can also invest in internationally traded bonds and domestic government debt $B_{t}^{f}$, where their initial endowment equals zero $B_{-1}^{f}=0$, leading to the Euler equations

$$
\beta R_{t}^{*} / \pi_{t+1}^{*}=\left(c_{t+1}^{*} / c_{t}^{*}\right)
$$

and $\beta\left(q_{t} / q_{t+1}\right)\left(1-\delta_{t+1}\right) R_{t} / \pi_{t+1}=\left(c_{t+1}^{*} / c_{t}^{*}\right)$ (implying 8 ), and the associated transversality conditions, which correspond to (9).

Perfectly competitive domestic firms produce the domestic consumption good with the linear technology $y_{H, t}=n_{t}$, leading to a profit maximizing labor demand satisfying $w_{t}=P_{H, t} / P_{t}$.

The government does not have access to lump-sum taxation. It borrows at home and abroad, $B_{t}=B_{t}^{h}+B_{t}^{f}$, raises tax revenues by taxing labor income, purchases the amount $g_{t}$ of the domestic good in each period, and receives central bank transfers $\tau_{t}^{m}$. Its budget constraint is

$$
B_{t} R_{t}^{-1}+P_{t} s_{t}=\left(1-\delta_{t}\right) B_{t-1},
$$

where $s_{t}$ denotes surpluses $s_{t}=\tau_{t} w_{t} n_{t}+\tau_{t}^{m}-\left(P_{t}^{H} / P_{t}\right) g_{t}$, which depends on the equilibrium allocation. Rewriting (11) in real terms, $\left(1-\delta_{0}\right) B_{-1} / P_{0}=b_{0} R_{0}^{-1}+s_{0}$ and $\left(1-\delta_{t+1}\right) b_{t} / \pi_{t+1}=b_{t+1} R_{t+1}^{-1}+s_{t+1}$, and iterating forward, yields the intertemporal government budget constraint

$$
\left(1-\delta_{0}\right) B_{-1} / P_{0}=\sum_{t=0}^{\infty} s_{t} \prod_{i=1}^{t} \frac{\pi_{i}}{\left(1-\delta_{i}\right) R_{i-1}}+\lim _{t \rightarrow \infty} b_{t} R_{t}^{-1} \prod_{i=1}^{t} \frac{\pi_{i}}{\left(1-\delta_{i}\right) R_{i-1}}
$$


We assume that the fiscal authority decides on taxes without guaranteeing repayment of initial debt. ${ }^{1}$ In particular, we assume that the labor income tax rate is set equal to a constant $\tau_{t}=\tau \in(0,1)$. For simplicity, we assume that government expenditures $g_{t}$ equal zero. Thus, sovereign default $\delta_{t}>0$ can occur when current and future discounted revenues from income taxation and from seigniorage are too low for given initial liabilities.

The central bank either sets the interest rate on bonds $R_{t}$ or the exchange rate $S_{t}$, and transfers seigniorage to the government: $M_{t}-M_{t-1}=P_{t} \tau_{t}^{m}$, such that the consolidated public sector budget constraint reads, $B_{t} R_{t}^{-1}+M_{t}+P_{t} \tau w_{t} n_{t}=\left(1-\delta_{t}\right) B_{t-1}+M_{t-1}$.

\section{Results}

In equilibrium, the markets for goods, labor, and assets (including government bonds $\left.B_{t}=B_{t}^{h}+B_{t}^{f}\right)$ clear. The resource constraint is

$$
P_{H, t} y_{H, t}-P_{t} c_{t}=S_{t}\left[\left(F_{t} / R_{t}^{*}\right)-F_{t-1}\right]-B_{t}^{f} R_{t}^{-1}+\left(1-\delta_{t}\right) B_{t-1}^{f} .
$$

Integrating (13) from period 0 onwards and using initial values $F_{-1}=0$ and $B_{-1}^{h}=B_{-1} \Rightarrow$ $B_{-1}^{f}=0$ as well as the foreign household transversality conditions leads to

$$
0=\sum_{t=0}^{\infty} \beta^{t} \frac{c_{0}}{c_{t}}\left(P_{H, t} y_{H, t}-P_{t} c_{t}\right)
$$

where we used $\Pi_{i=1}^{t} \pi_{i} /\left(\left(1-\delta_{i}\right) R_{i-1}\right)=\beta^{t} c_{0} / c_{t}$. We assume that the domestic economy is small in the sense that its exports are negligible for the foreign economy and that the foreign goods price $P_{F, t}^{*}$ equals the foreign price index, $P_{t}^{*}=P_{F, t}^{*}$ (see e.g. [2]). Then, the domestic price index $P_{t}=P_{H, t}^{1-\vartheta} P_{F, t}^{\vartheta}$ and the law of one price $P_{F, t}=S_{t} P_{t}^{*}\left(=q_{t} P_{t}\right)$ imply $P_{H, t} / P_{t}=q_{t}^{\vartheta /(\vartheta-1)}$. Using the latter to rewrite foreign and domestic demand for domestic goods $(2)$ as $c_{H, t}^{*}=\vartheta^{*} q_{t}^{1 /(1-\vartheta)} c_{t}^{*}$ and $c_{H, t}=(1-\vartheta) q_{t}^{\vartheta /(1-\vartheta)} c_{t}$, domestic goods market clearing $y_{H, t}=c_{H, t}+c_{H, t}^{*}$, can be rewritten as

$$
y_{H, t}=(1-\vartheta) q_{t}^{\frac{\vartheta}{1-\vartheta}} c_{t}+\vartheta^{*} q_{t}^{\frac{1}{1-\vartheta}} c_{t}^{*}
$$

Like under perfect international risk sharing (see e.g. [2]), (7) and (10) can be combined to $\frac{c_{t+1}}{c_{t}}=\frac{q_{t+1} c_{t+1}^{*}}{q_{t} c_{t}^{*}} \forall t \geq 0$, implying that domestic and foreign consumption (in terms of

\footnotetext{
${ }^{1}$ In fact, income tax revenues are bounded by the maximum of the Laffer curve.
} 
the domestic consumption bundle) are proportional:

$$
c_{t}=\xi q_{t} c_{t}^{*}
$$

To determine the constant $\xi$, we use that (15) together with (16) and $P_{t} / P_{H, t}=q_{t}^{\frac{\vartheta}{1-\vartheta}}$ lead to $P_{H, t} y_{H, t}=\left(1-\vartheta+\vartheta^{*} / \xi\right) P_{t} c_{t}$. Comparing the latter with (14) immediately shows that $\xi=\vartheta^{*} / \vartheta>0$, such that trade is balanced $P_{H, t} y_{H, t}=P_{t} c_{t} \forall t \geq 0$. We further use the transversality conditions for domestic and foreign holdings of public debt and $w_{t} n_{t}=c_{t}$, to rewrite (12) as

$$
\left(1-\delta_{0}\right) B_{-1} / P_{0}=\sum_{t=0}^{\infty} \beta^{t} \frac{c_{0}}{c_{t}}\left(\tau c_{t}+\tau_{t}^{m}\right)
$$

Given balanced trade $S_{t}\left[\left(F_{t} / R_{t}^{*}\right)-F_{t-1}\right]=B_{t}^{f}-B_{t-1}^{f}$ (see 13) and the consolidated public sector budget constraint, the cash constraint (4) reduces to $P_{t} c_{t} \leq M_{t}+P_{t} \tau w_{t} n_{t} \Rightarrow$ $c_{t}(1-\tau) \leq m_{t}$. Hence, under a binding cash-constraint, which requires $S_{t+1} / S_{t}>1 / R_{t}^{*}$, central bank transfers satisfy $\tau_{t}^{m}=(1-\tau)\left(c_{t}-c_{t-1} \pi_{t}^{-1}\right) \forall t \geq 1$ such that (17) can be rewritten as

$$
\left[\left(1-\delta_{0}\right) B_{-1}+M_{-1}\right] / P_{0}=c_{0}\left[(1-\beta)^{-1}-(1-\tau) \sum_{t=0}^{\infty} \beta^{t+1}\left(P_{t} c_{t}\right) /\left(P_{t+1} c_{t+1}\right)\right]
$$

Since the domestic economy is small, the sequences $\left\{R_{t}^{*}>1, c_{t}^{*}>0, P_{t}^{*}>0\right\}_{t=0}^{\infty}$, which have to be consistent with $(10)$, are exogenously given. Substituting out $w_{t}\left(=q_{t}^{\vartheta /(\vartheta-1)}\right)$ and $q_{t}$ in (5) and (16), we can define an equilibrium as follows.

Definition 1 A perfect foresight equilibrium under a binding cash-constraint is a set of sequences $\left\{c_{t} \geq 0, S_{t}>0, P_{t}>0, R_{t}\left(1-\delta_{t+1}\right)\right\}_{t=0}^{\infty}$ and an initial default rate $\delta_{0}$ satisfying

$$
\begin{aligned}
c_{t+1} / c_{t} & =\beta\left(1-\delta_{t+1}\right) R_{t} /\left(P_{t+1} / P_{t}\right), \\
\left(1-\delta_{t+1}\right) R_{t} & =\left(S_{t+1} / S_{t}\right) R_{t}^{*} \\
\psi c_{t}^{\frac{1}{1-\vartheta}} & =\left(\widetilde{c}_{t}^{*}\right)^{\frac{\vartheta}{1-\vartheta}} \frac{1-\tau}{R_{t}\left(1-\delta_{t+1}\right)}, \\
S_{t} & =P_{t} c_{t} /\left(P_{t}^{*} \widetilde{c}_{t}^{*}\right),
\end{aligned}
$$

(18), where $\widetilde{c}_{t}^{*}=\vartheta^{*} c_{t}^{*} / \vartheta$, and a monetary policy setting $R_{t} \geq 1$ or $S_{t} \geq 0$, given $\left\{R_{t}^{*}>1\right.$, $\left.c_{t}^{*}>0, P_{t}^{*}>0\right\}_{t=0}^{\infty}, B_{-1}>0$, and $M_{-1}>0$. 
Condition (21) shows that consumption is affected by the effective rate of return on bonds $\left(1-\delta_{t+1}\right) R_{t}$ due to the transactions friction induced by the cash constraint (see 4 and 5 ). Once consumption is determined, the real exchange rate, working time, inflation, and the effective rate of return on bonds are determined as well.

Corollary 1 Given $\left\{c_{t}>0\right\}_{t=0}^{\infty},\left\{q_{t}\right\} \forall t \geq 0$ is determined by (16), $\left\{y_{H, t}=n_{t}\right\} \forall t \geq 0$ by (15), $\left\{\pi_{t}=P_{t} / P_{t-1}>0\right\} \forall t \geq 1$ by (19), and $\left\{\left(1-\delta_{t+1}\right) R_{t}\right\} \forall t \geq 0$ by (21).

A policy of setting the interest rate $R_{t}$ and letting the exchange rate flow fails to determine the equilibrium, which has been shown for a closed economy by [5]. Consider, for example, a conventional interest rate policy where $R_{t}$ is set either in an exogenous way or contingent on macroeconomic indicators, like inflation or output, which both can be expressed in terms of consumption (see corollary 1). The equilibrium allocation is then indetermined, since $\left(1-\delta_{t+1}\right) R_{t}$ rather than the contractual rate $R_{t}$ affects the consumption decision (see 21 ), while the repayment rate can only be determined for the initial period $1-\delta_{0}$ via (18). This result differs from the FTPL case (see [6] and [8]), where default is ruled out by assumption, even when the government does not guarantee intertemporal solvency. In this case $\left(\delta_{t}=0\right)$, an interest rate peg uniquely determines consumption by $(21)$, inflation by (19), the initial price level by (18) and the exchange rate by (22).

Here, households account for the possibility of default when they invest in domestic bonds (see 19). Yet, the central bank can nevertheless guarantee a uniquely determined equilibrium, which is independent of default, by pegging the exchange rate $S_{t}=S .^{2}$ Then, $\left(1-\delta_{t+1}\right) R_{t}$ is determined by (20), consumption by (21), the price level by (22), consistent with (19), and the initial default rate by (18). ${ }^{3}$

Proposition 1 Under a fixed exchange rate the equilibrium is determined and the allocation of resources is independent of sovereign default. Under a (conventional) interest rate policy and a floating exchange rate, the equilibrium is indetermined.

By pegging the exchange rate, the equilibrium allocation is shielded against sovereign default risk. While default can still occur, this policy guarantees that the allocation and goods prices do not depend on default expectations or the governments' default decision

\footnotetext{
${ }^{2}$ In this case, the cash-constraint is ensured to be binding, since (20) and $R_{t}^{*}>1$ imply $\mu_{t}>0$.

${ }^{3}$ For constant foreign variables the initial default rate is simply given by $\delta_{0}=1-\left[S\left(P^{*} \widetilde{c}^{*}\right)(1-\right.$ $\left.\left.(1-\tau) / R^{*}\right)(1-\beta)^{-1}-M_{-1}\right] / B_{-1}$ and decreases with the nominal exchange rate.
} 
(which is not modelled here). If, for example, the government decides in each period whether to default or not according to some decision rule (e.g. a tax-to-debt rule, see [7]), households will base their expectations upon this "default policy". The equilibrium allocation would then be affected by default expectations, if the central bank sets $R_{t}$.

\section{Conclusion}

We have shown that a fixed, but not to a floating, exchange rate guarantees equilibrium determinacy under sovereign default risk. By "importing" stable interest rates, the equilibrium allocation is shielded against default expectations, which provides a strong argument in favor of exchange rate pegs, when fiscal policy does not to guarantee debt repayment.

\section{References}

[1] B. Daniel, The Fiscal Theory of the Price Level in an Open Economy, J. Monet. Econ. 48 (2001), 293-308.

[2] J. Gali, and T. Monacelli, Monetary Policy and Exchange Rate Volatility in a Small Open Economy, Rev. Econ. Stud. 72 (2005), 707-734.

[3] O. Jeanne, and A. Guscina, Government Debt in Emerging Market Countries: A New Data Set, IMF Working Paper WP/06/98 (2006).

[4] E. Loyo, Tight Money Paradox on the Loose: A Fiscalist Hyperinflation, J.F. Kennedy School of Government, (2001) Harvard University.

[5] A. Schabert, Monetary Policy under a Fiscal Theory of Sovereign Default, J. Econ. Theory 145 (2010), 860-868.

[6] C. Sims, A Simple Model for the Study of the Determination of the Price Level and the Interaction of Monetary and Fiscal Policy, Econ. Theory 4 (1994), 381-399.

[7] M. Uribe, A Fiscal Theory of Sovereign Risk, J. Monet. Econ. 53 (2006), 1857-1875.

[8] M. Woodford, Monetary Policy and Price Level Determinacy in a Cash-in-Advance Economy, Econ. Theory 4 (1994), 345-380. 

